\title{
Biosynthesis of Epoxydon and Related Compounds by Phyllosticta sp.
}

\author{
Kensuke Nabeta, Akitami Ichifiara and Sadao SaKamura \\ Department of Agricultural Chemistry, Hokkaido University, Sapporo \\ Received July 22, 1974
}

\begin{abstract}
The tetraketide origin of epoxydon I produced by Phyllosticta sp. is established by ${ }^{13} \mathrm{C}$ NMR measurement on labelled epoxydons obtained from $1^{13} \mathrm{C}$ - and $2^{-18} \mathrm{C}$-acetate. The chlorinating mechanism of epoxydon to form non-enzymatically compound IV, V and VI was also confirmed by exposing epoxydon to the culture broth.
\end{abstract}

A most abundant metabolite, epoxydon ${ }^{1,2)}$ (phyllosinol) (I in Scheme I) has been isolated from Phyllosticta sp., ${ }^{1)}$ a pathogenic fungus of red clover. ${ }^{3)}$ The fungus also produces 6methylsalicylic acid (II) and gentisyl alcohol (III). It has been noted that these compounds are biosynthesized via polyketide pathway in other organisms. ${ }^{5)}$ These findings let us to postulate that epoxydon are most probably biosynthesized via tetraketide intermediate, although shikimate pathway is presumptive one. The results of experiments with ${ }^{13} \mathrm{C} \mathrm{NMR}$ measurements of labelled epoxydon incorporated with ${ }^{13} \mathrm{C}$-sodium acetates now confirmed that epoxydon was derived from gentisyl alcohol via a tetraketide chain and reported in a preliminary form. ${ }^{6)}$ Feeding experiments of ${ }^{14} \mathrm{C}$ gentisyl alcohol, which is postulated to be an immediate or very near precursor of epoxydon, was carried out by using the well washed mycelial mats from 14 days -old culture. Gentisyl alcohol was incorporated $(25 \%)$ into epoxydon. This rather low incorporation may be due to the endogeneous formation of epoxydon. In fact, it has been shown that five mycelial mats placed on the surface of each $15 \mathrm{ml}$ desalted water formed ca. $2 \mathrm{mg}$ of epoxydon, the amount of which was estimated from UV absorption. Either starvation of mycelia or elongation of the incubating period did not diminish endogeneous formation of epoxydon. These observations serve to emphasize that epoxydon was biosynthesized from gentisyl alcohol. The tetraketide origin of epoxydon was confirmed as follows.

The ${ }^{13} \mathrm{C}$-assignments of signals of natural epoxydon are shown in the ' $\mathrm{H}$ noise decoupled FT spectrum in Figure (1a) and Table I.

Table I. ${ }^{13} \mathrm{C}$ NMR Data for ${ }^{13} \mathrm{C}$ Labelled EPOXYDON

\begin{tabular}{lrcl}
\hline a) & Shift & $2^{-{ }^{13} \mathrm{C}}$ Acetate & $\mathbf{1}^{13} \mathrm{C}$ Acetate \\
\hline $\mathrm{C}-1$ & -66.5 & -66.4 & - \\
$\mathrm{C}-2$ & -6.7 & - & -6.9 \\
$\mathrm{C}-3$ & -13.4 & -13.3 & - \\
$\mathrm{C}-4$ & 63.3 & - & 62.8 \\
$\mathrm{C}-5$ & 73.5 & 73.7 & - \\
$\mathrm{C}-6$ & 74.6 & - & 74.5 \\
$\mathrm{C}-7$ & 69.3 & 69.4 & - \\
\hline
\end{tabular}

a) Number of positions are given in Scheme 1.

Peaks at $\delta 63.3(\mathrm{ppm})$ and 69.3 were ascribed to a secondary alcoholic carbon $(\mathrm{C}-4)$ and a primary alcoholic carbon (C-7) respectively. $\mathrm{CW}$ irradiation ${ }^{7}$ at the protons of methyl iodide in $\mathrm{MeOH}$ gives a doublet (the residual splitting: $J=38.6 \mathrm{~Hz}$ ) in the former and triplet $(J=36.6)$ in the later (Fig. 1(b)). Peaks at $\delta 73.5$ and $\delta 74.6$ were assigned to epoxy-carbon (C-6 and $\mathrm{C}-5$ respectively) by $\mathrm{CW}$ decoupling ${ }^{13} \mathrm{C}-\mathrm{NMR}$. Thus the 'H-spectrum of epoxydon in $\mathrm{CD}_{3} \mathrm{OD}$ shows $6-\mathrm{H}$ ( $\delta 3.37$ from TMS) separated further from the irradiating field at $o 2.12$ (ppm from TMS) than 5-H (o 3.77). In the $\mathrm{CW}$ spectrum of epoxydon, the epoxycarbons $\mathrm{C}-6$ and $\mathrm{C}-5$ appear as doublets and the assignments are based on $J=44.7$, smaller residual coupling, as observed for $\mathrm{C}-6$ relative 


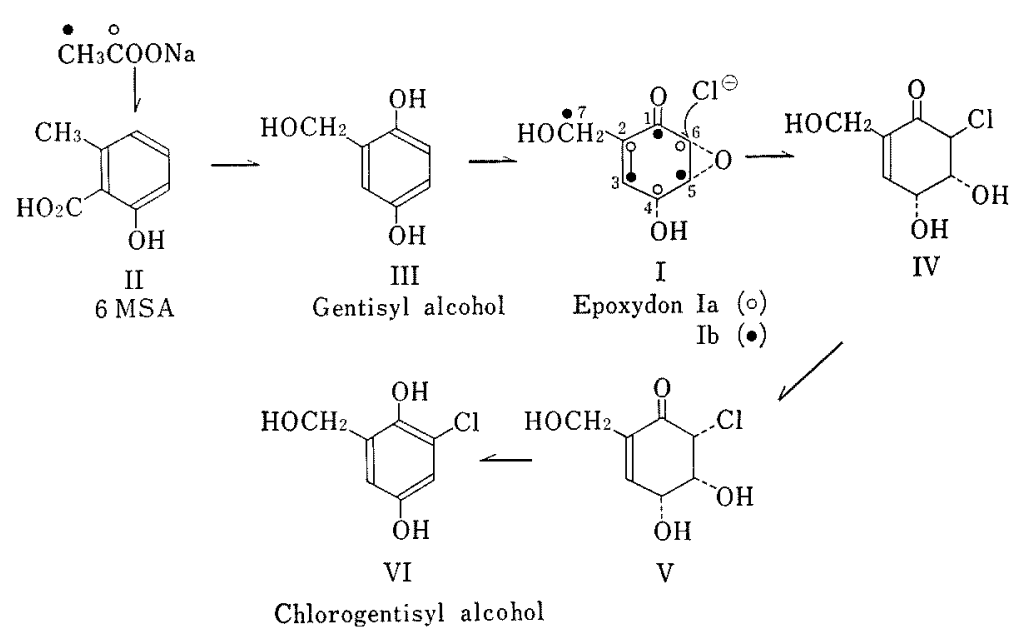

SCHEME 1. Biosynthesis of Epoxydon and Related Compounds.

to $J=4.6 .2$ for $\mathrm{C}-5$ according to Ernst ${ }^{8)}$ equation, assuming the same $J_{\mathrm{CH}}$ for them. Of the two tertiary centers in $\alpha, \beta$-unsaturated ketone system, peak at $\delta-66.5$ was ascribed to carbonyl carbon and $\delta-6.7$ to $\alpha$ carbon (C-2). $\quad \beta$-Carbon $(\mathrm{C}-3)$ resonated at $\delta-13.3$ shows doublet $(J=46.8)$ in $\mathrm{CW}$ decoupling ${ }^{13} \mathrm{C}-\mathrm{NMR}$.

The epoxydon (Ia) and (Ib) biosynthesized from each $400 \mathrm{mg}$ of sodium $1-{ }^{13} \mathrm{C}(88 \%)$ and $2{ }^{13} \mathrm{C}$-acetate $(86 \%)$ gives the ${ }^{13} \mathrm{C}$ NMR spectra Fig. 1(d) and Fig. 1(c) respectively.* The former spectrum was measured by ' $\mathrm{H}$ noise decoupling with multiscan and the later, by FT system. Assignment of their signals demonstrated that $\mathrm{C}-1, \mathrm{C}-3, \mathrm{C}-5$ and $\mathrm{C}-7$ of epoxydon were derived from the methyl carbon and $\mathrm{C}-2, \mathrm{C}-4$ and $\mathrm{C}-6$ from the carboxyl carbon of the acetate. The ${ }^{\prime} \mathrm{H}-{ }^{19} \mathrm{C}$ satelite bands for $3-\mathrm{H}$ in $\mathrm{Ia}(\mathrm{JCH} 164 \mathrm{~Hz})$ and $6-\mathrm{H}$ in $\mathrm{Ib}(\mathrm{JCH} 191 \mathrm{~Hz})$ in the 'H NMR spectra $(90 \mathrm{MHz})$ support this labelling pattern.

This labelling pattern confirms the polyketide origin of epoxydon. Additionally chlorinated substances (IV, V and VI) have been founded in the culture broth of this fungus. ${ }^{9 !}$

Sequin-Frey and Tamm suggested the hypothetical chlorination mechanism from gen-

\footnotetext{
* The incorporation of ${ }^{13} \mathrm{C}$-acetate into $\mathrm{Ia}$ and $\mathrm{Ib}$ was estimated to be $6.6 \%$ efficiency according to the primary experiment using ${ }^{14} \mathrm{C}$-acetate.
}

tisyl alcohol to chlorogentisyl alcohol (VI) by the action of enzyme such as chloroperoxidase. $^{10,11\}}$ However known chemical transformation of epoxydon to chlorogentisyl alco$\mathrm{hol}^{9)}$ and rather higher concentration of chloric anion (estimated ca. $130 \mathrm{ppm}$ ) in the used culture medium indicates the possibility of nonenzymic formation of chlorogentisyl alcohol from epoxydon. Experiments without fungus inoculation as mentioned below gave a clear indication that chlorogentisyl alcohol is formed from epoxydon.

When $85 \mathrm{ml}$ of concentrated potato extract including $85 \mathrm{mg}$ of epoxydon was allowed to stand for 6 days, chlorogentisyl alcohol (a main component) and compound (V) in the acetone extracts were observed on TLC. Crystalline chlorogentisyl alcohol $(0.7 \mathrm{mg})$ was isolated by a chromatographic separation over silicic acid and its IR spectrum was identical to that of the authentic specimen. On the other hand, when the solution mixed with $430 \mathrm{mg}$ of epoxydon in $430 \mathrm{ml}$ of the concentrated medium was allowed to stand for $60 \mathrm{hr}$, crystalline material $(5 \mathrm{mg})$ of compound IV whose IR spectrum was identical to that of authentic specimen was isolated as a major chlorinated compound and at the same time $23 \mathrm{mg}$ of epoxydon was recovered. The existence of not only chlorogentisyl alcohol but also compound IV and $\mathrm{V}$ indicates that chlorogentisyl 
FIG. 1.

a) ' $\mathrm{H}$ noise-decoupled ${ }^{13} \mathrm{C}$-Ft spectrum of $224 \mathrm{mg}$ of epoxydon (I) in $1.2 \mathrm{ml}$ of $\mathrm{CH}_{3} \mathrm{OH}$ at $22.6 \mathrm{MHz}$; sweep time $800 \mathrm{sec}$, number of scan 200 times, pulse angle $25 \mu \mathrm{sec}$, filter $8 \mathrm{KHz}$.

b) $\mathrm{CW}$ decoupled ${ }^{13} \mathrm{C}$ NMR spectrum of epoxydon. $224 \mathrm{mg}$ of epoxydon/1.2 $\mathrm{ml}$ of $\mathrm{CH}_{3} \mathrm{OH}$ at $22.6 \mathrm{MHz}$; sweep time $800 \mathrm{sec}$, number of scan 6266 times, pulse angel $25 \mu \mathrm{sec}$, filter $8 \mathrm{KHz}$.

c) ' $\mathrm{H}$ noise-decoupled ${ }^{13} \mathrm{C}$-Ft spectrum of $97 \mathrm{mg}$ of epoxydon $/ 1.5 \mathrm{ml}$ of $\mathrm{CH}_{3} \mathrm{OH}$ biogenetically enriched with ${ }^{13} \mathrm{C}$ from ${ }^{2-13} \mathrm{C}$ acetate at $22.6 \mathrm{MHz}$, sweep time $800 \mathrm{sec}$, number of scan 50 times, pulse angle $25 \mu \mathrm{sec}$, filter $8 \mathrm{KHz}$. d) 'H-noise-decoupled ${ }^{13} \mathrm{C}$-spectrum of $40 \mathrm{mg}$ of epoxydon from $1{ }^{13} \mathrm{C}$ acetate in $1.0 \mathrm{ml}$ of $\mathrm{CH}_{3} \mathrm{OH}$ with 1208 scans at $40 \mathrm{sec} / \mathrm{scan}$ at $22.6 \mathrm{MHz}$. Chemical shifts were measured relative to the ${ }^{13} \mathrm{C}$ signal of methanol and converted to ppm from benzene using the relationship $\delta \mathrm{c}$ (benzene) $=\delta$ $(\mathrm{MeOH})+79.0 \mathrm{ppm}$.

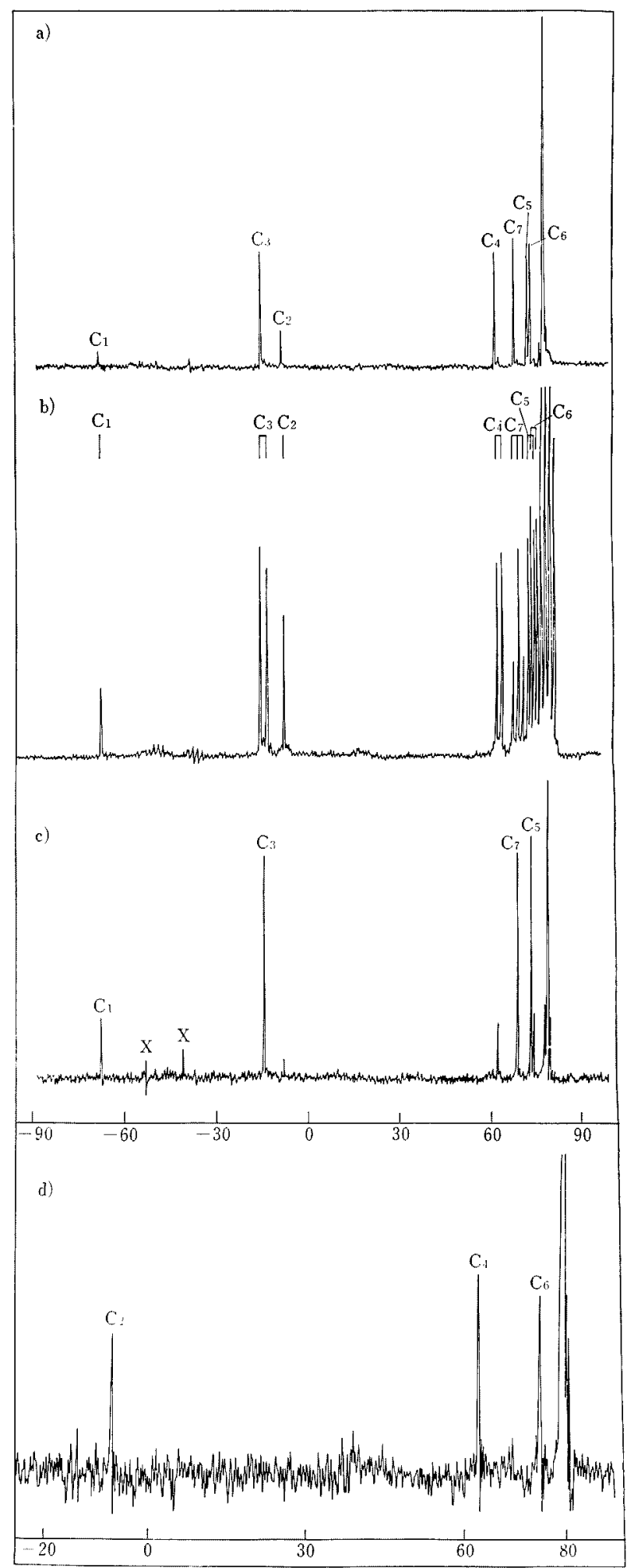


alcohol was formed non-enzymically in culture medium through the way established chemically and depicted in Scheme 1. This process was confirmed by the fact that by shortening of exposing time to the culture medium, compound IV was obtained as major product among the chlorinated compounds.

This experimental results indicate the most possible process concerning formation of chlorogentisyl alcohol from epoxydon summerized as Scheme 1. These results might be expanded to include the mechanism of production of chlorogentisyl alcohol by Phoma ${ }^{10)}$ sp., since this species also gives epoxydon. ${ }^{2)}$ It is, however, not obvious whether other halogenated compounds, such as erdin, geodin, dihydrogeodin, ascochlorin or geodoxin ${ }^{5)}$ are formed in the same manner as in case of chlorogentisyl alcohol by Phyllosticta sp.

\section{EXPERIMENTAL}

\section{${ }^{14} \mathrm{C}$-Labelled epoxydon}

Phyllosticta sp. used in this experiment was isolated by Narita. Inocula were grown on the slant of potatoglucose agar for 6 days. Growth was in $500 \mathrm{ml}$ flasks holding $200 \mathrm{ml}$ of potato extract (potato: water $150 \mathrm{~g}$ / liter) containing $\mathrm{D}$-glucose $(1.5 \%)$ and ${ }^{14} \mathrm{C}$-sodium acetate $(100 \mathrm{mg}$ : $250 \mathrm{million} \mathrm{cpm} / \mathrm{mg}$ ) for 20 days at $25^{\circ} \mathrm{C}$. Medium from the flask was added $6 \mathrm{~g}$ carbon -cellite $(1: 1)$ mixture, the slurry was packed in a column and then washed with water. ${ }^{14} \mathrm{C}$-Labelled epoxydon could be eluted with acetone $(60 \mathrm{ml})$. Then purified crystalline epoxydon $(1.26 \mathrm{mg}, \quad 3180 \mathrm{cpm} / \mathrm{mg})$ was obtained by chromatographic separation using a silicic acid column $(10 \mathrm{~g})$ eluted with ethyl acetate-chloroform (2:8) followed by crystallization.

\section{${ }^{13} C$-Epoxydons (Ia and Ib)}

Mycelia were grown in four $500 \mathrm{ml}$ flasks containing the same potato D-glucose medium, as mentioned above, to which was added $100 \mathrm{mg} 11^{-13} \mathrm{C}$ sodium acetate $(88 \%)$ or $2-{ }^{13} \mathrm{C}$ sodium acetate $(86 \%)$ for 20 days at $25^{\circ} \mathrm{C}$. The combined filtrates from four flasks were added to $30 \mathrm{~g}$ carbon-cellite $(1: 1)$ mixture, and the slurry was packed in a column and then washed with water. ${ }^{13} \mathrm{C}$ Labelled epoxydon was obtained by elution with acetone, then chromatographic separation using a silicic acid $(25 \mathrm{~g})$ column with ethyl acetate-chloroform (2:8) followed by crystallization from ethyl acetate gave $1{ }^{-13} \mathrm{C}$ or $2-{ }^{13} \mathrm{C}$-acetate incorporated epoxydon, $(30 \mathrm{mg}$, $80 \mathrm{mg}$ ), $\mathrm{mp} 78^{\circ} \mathrm{C}$, in a pure crystalline state.

\section{Preparation of ${ }^{14} \mathrm{C}$-labelled gentisyl alcohol from epoxy. don}

Gentisyl alcohol was prepared in a modified method described by Sigg et al. ${ }^{11}$ Potassium iodide $(200 \mathrm{mg})$ was added to $40 \mathrm{mg}$ of radioactive epoxydon in acetic acid $(30 \mathrm{ml})$. The resulting solution was allowed to stand for $40 \mathrm{~min}$ at $80^{\circ} \mathrm{C}$. After being cooled in an ice-bath, the solution was poured into a cooled aqueous solution of sodium bisulfate $(40 \mathrm{mg} / 35 \mathrm{ml})$. After six or seven seconds, the aqueous solution was extracted three times with $35 \mathrm{ml}$ portions of ethyl acetate. The combined solution was dried over sodium sulfate. The solvent was removed and the residue was chromatographed over a silicic acid column eluted with ethyl acetate-chloroform $(8: 2)$. The crystalline gentisyl alcohol $(6.6 \mathrm{mg}$, yielded $19 \%)$ was obtained. The crystals were mixed with non-labelled gentisyl alcohol (6.7 $\mathrm{mg}$ ) and recrystallized from $\mathrm{CHCl}_{3}$. Gentisyl alcohol thus obtained has $810 \mathrm{cpm}$ of specific radio-activity.

\section{Conversion of gentisyl alcohol to epoxydon}

Mycelial mats from 14 days culture were grown in $500 \mathrm{ml}$ flask each containing the same growing medium as employed previously. After washing with distilled water thoroughly, ten mycelial mats were placed on $15 \mathrm{ml}$ of aqueous solution which contained the radioactive gentisyl alcohol $(810 \mathrm{cpm} / \mathrm{mg})$ in $0.0067 \%$ concentration of the aq. solution, and incubated at $25^{\circ} \mathrm{C}$ for $8 \mathrm{hr}$. After removal of mycelial mats, the incubated mixture was subjected to column chromatography with carbon-celite and acetone followed by column chromatography with silicic acid and chloroform-ethyl acetate (2:8). Pure crystals of epoxydon ( $2 \mathrm{mg}, 190$ $\mathrm{cpm} / \mathrm{mg}$ ) were obtained by recrystallization from ethyl acetate-chloroform.

\section{Non enzymic chlorination of epoxydon}

The potato extract $(150 \mathrm{~g} /$ liter) containing $1.5 \% \mathrm{D}$ glucose was concentrated to one-tenth of its original volume and then autoclaved. To $85 \mathrm{ml}$ of this solution, aqueous epoxydon solution, $86 \mathrm{mg} / 10 \mathrm{ml}$, sterilized by filtration through a membrane filter was added. This mixture was allowed to stand at $25^{\circ} \mathrm{C}$ for 6 days. In other case, epoxydon solution, $430 \mathrm{mg} / 10 \mathrm{ml}$ was added to $430 \mathrm{ml}$ of concentrated potato extract and the mixture was allowed to stand for $60 \mathrm{hr}$. Then, positive substances for Folin-Ciocalteu reagent from each solution were isolated by a carbon-celite column chromatography eluting with acetone, and identified as IV, V and VI.

Acknowledgement. We thank Dr. Kuniyoshi Huzieda (Hitachi Seisakusho Co. Ltd) for the ${ }^{13} \mathrm{C}$ NMR measurements. 


\section{REFERENCES}

1) A. Closse, R. Mauli and H. P. Sigg, Helv. Chim. Acta, 49, 204 (1966).

2) S. Sakamura, H. Niki, Y. Obata, R. Sakai and T. Matsumoto, Agr. Biol. Chem., 33, 698 (1969).

3) R. Sakai, R. Sato, H. Niki and S. Sakamura, Plant \& Cell. Physiol., 11, 907 (1970).

4) S. Sakamura, T. Chida, J. Ito and R. Sakai, Agr. Biol. Chem., 35, 445 (1971).

5) "Fungal Metabolite," W.B. Turner, Academic Press, New York, 1971, p. 86.
6) K. Nabeta, A. Ichihara and S. Sakamura, Chem. Commun., 814 (1973).

7) M. Tanabe, T. Hamasaki, D. Thomas and L. Jahnson, J. Amer. Chem. Soc., 93, 272 (1971).

8) R. R. Ernst, J. Chem. Phy., 45, 3845 (1966).

9) a) S. Sakamura, K. Nabeta, S. Yamada and A. Ichihara, Agr. Biol. Chem., 35, 1639 (1971); b) S. Sakamura, K. Nabeta, S. Yamada and A. Ichihara, Agr. Biol. Chem., 39, 403 (1975).

10) M. Sequin-Frey and Ch. Tamm, Helv. Chim. Acta, 54, 851 (1971).

11) J. R. Beckwith and L. P. Hager, J. Biol. Chem., 238, 3091 (1963). 